\title{
Evaluación del Producto Antiviral Av-100 y Citrol en el Control del Virus Y (PVY) de la Papa
}

\author{
Boris Contreras K. ${ }^{1}$, Andrés Contreras M. ${ }^{2}$
}

\begin{abstract}
Resumen
Se evaluó la efectividad de un agente antiviral, "AV-100" y un sinergista de su acción, "Citrol", en plantas de papa infectadas con el virus $\mathrm{Y}$.
\end{abstract}

Las dosis de AV-100 fueron equivalentes a 0-1.5-3 y $4.5 \mathrm{l} / \mathrm{ha}$, cada dosis se aplicó con y sin Citrol. Además se evaluó el momento de aplicación de AV-100, el cual fue realizado a los 25 y 50 días después de la emergencia de los brotes, y 25 días después de emergencia de papas cosechadas, se realizó la última evaluación.

La determinación de la presencia de virus se realizó en el follaje inicial y en plantas de primera descendencia, vía DAS-ELISA, y espectrofotómetro para su cuantificación.

De las dosis de AV-100 evaluadas, ninguna eliminó el PVY, sin embargo, el nivel a 4.5 I/ha sin Citrol provocó una reducción de un $77 \%$ de la cantidad de virus en la planta.

El uso de Citrol no mostró diferencias, a excepción del tratamiento con 4.5 l/ha de AV-100, nivel en que la adición de Citrol provocó un aumento de la concentración de virus en la planta. Además, no hubo un mayor efecto con dos aplicaciones de éste producto.

Palabras claves adicionales: Antiviral, sinergista, PVY, efecto sinérgico.

1 Parte de tesis para optar al título de Ingeniero Agrónomo. Universidad Austral de Chile. Valdivia, Chile.

2 Instituto de Producción y Sanidad Vegetal, Facultad de Ciencias Agrarias, Universidad Austral de Chile. Casilla 567, Valdivia, Chile. Email: acontrer@uach.cl. 


\title{
Evaluation of the Antivirus Product AV-100 and Citrol for the Control of Potato Virus Y (PVY)
}

\begin{abstract}
Summary
The purpose of this research was to evaluate the effectiveness of a product derived from natural resins, with antiviral activity labeled as "AV-100", and the synergic agent "Citrol". The evaluation was conducted on potato plants CV. Melita that were systematically infected with potato virus $Y(P V Y)$.

AV-100 was tested in concentrations of $0,1.5,3$ and $4.5 \mathrm{l} / \mathrm{ha}$. Each rate was applied alone or in combination with Citrol. The AV-100's application time was also evaluated after potato sprouting (one application was done after 25 days and a second one, after 25 and 50 days of sprout emergence, etc.)

The presence of the PVY in the plants was determined by ELISA tests, before applying AV-100, and then every 25 days, (25, 50 and 75 days after plant emergence). ELISA tests were also conducted with sprouts from tubers collected from treatments of the field assay.

Up to $77 \%$ of virus infection reduction was observed with $4.5 \mathrm{l} / \mathrm{ha}$. of AV-100; however, complete eradication from plant tissues did not occur.

Results indicated that there was no synergic effect by adding Citrol. The only exception was noted with 4,5 I/ha of AV-100, in which the application of Citrol produced an increase of the amount of virus in the plant tissues. It was also concluded that two applications of Citrol did not reduce the virus concentration on treated plants, when compared to one application.
\end{abstract}

Additional index words:

Antivirus, synergy, PVY.

\section{Introducción}

La papa es una planta sometida a una alta presión de enfermedades, plagas de todo tipo y por su forma de propagación asexual transmite e incrementa en alta medida los problemas viróticos. 
Las enfermedades virales son difícilmente reconocibles ya que la expresión de los síntomas visuales dependen en gran medida de las condiciones del medio donde se encuentren y del manejo que se haga al cultivo. Estas enfermedades reducen el vigor de la planta y la degeneran, por lo tanto, afectan su rendimiento provocando finalmente una pérdida del potencial productivo.

El control de las enfermedades virosas se realiza mediante la protección del semillero en producción de papa-semilla certificada, la erradicación de plantas o saneamiento, el control de vectores y la eliminación del virus de la planta por medio de termoterapia y cultivo de meristemas y la resistencia genética $(14,2,3)$.

Paralelamente se han evaluado fármacos de acción antiviral, los que se han incrementado sobre todo en los últimos 10 años, más bien como una reacción a la pandemia de la infección por el virus de la inmunodeficiencia humana (VIH) (8), orientando su búsqueda, en primer lugar, a aquellos productos que han mostrado tener actividad viricida en animales $(5,6)$.

Algunos compuestos que se citan, han sido Ribavirin (Virazole) y 2,4Dioxohexahidro-1,3,5-triazina (DTH), los cuales han sido usados en conjunto con cultivo de meristemas $(13,15)$. Otros extractos vegetales que han mostrado relativo éxito son: Boeerharia diffusa (18) Pseuderanthemun bicolor (19) Lentinus edodes, Yucca recurvifolia (9), Cymopsis tetragonoloba (11). Además Khan y Zaim (1992) evaluaron extractos de hojas de algunas plantas como Operculina turpethum y bulbos de Scilla indica, que han demostrado tener propiedades antivirales induciendo resistencia sistémica contra el virus del mosaico del tabaco (TMV), el "sunnhemp rosette virus" (SRV), el "datura shoestring virus" (DSV), y el "tómalo spotted wilt virus" (TSWV).

En la presente investigación se evalúa la acción del producto AV-100, fabricado por la firma FUMEX Ltda. de Chile, catalogado como un agente antiviral sistémico de rápido control de enfermedades producidas por virus, y un sinergista de su acción de nombre distintivo "Citrol". 


\section{Materiales y Métodos}

Se utilizó el producto AV 100 obtenido a partir de resinas naturales de acción alelopática conjugadas con ácidos carboxílicos, que está compuesto por resinas alelopáticas AV (1.5\%), fito-ácidos (5.0\%), carbohidratos (5.0\%) y aditivos inertes de aspersión (88.55). Como producto de acción sinérgica se empleó con "Citrol", que consiste en una mezcla del antivirus, AV 100, sales amoniacales de aminoácidos y extracto de semilla de pomelo.

El experimento consistió de 16 tratamientos: oportunidad de aplicación (2), dosis del producto (6) y uso de producto sinérgico (2), con 8 repeticiones, en las cuales se evaluó el efecto del "AV 100", del sinergista "Citrol" y de los momentos de aplicación (Tabla 1) en el CV. de papa Melita provenientes de plantas infectadas con PVY en invernadero. El diseño experimental correspondió a un ordenamiento completamente al azar en un diseño factorial.

Se utilizó Rindite (7 partes de cloroetanol: 3 partes de 1.2 dicloroetanol, 1 parte de tetracloruro de carbono), en dosis de $1 \mathrm{cc}$. por kilo de papas para romper la dormancia de los tubérculos.

La determinación de virus fue realizada por ELISA (enzime linked inmunosorbent assay), con el protocolo del Centro Internacional de la Papa-(4), modificado el tampón de extracción, de cobertura (leche en polvo descremada por albúmina de huevo).

Para la cuantificación del virus se usó un Espectrofotómetro de $405 \mathrm{~nm}$ de longitud de onda. Debido a que los controles negativos mostraron variación en la intensidad de coloración del sustrato de la enzima, se determinó como límite superior negativo al promedio del valor sano obtenido sumándole 0.05 como valor preestablecido. Toda lectura superior a ésta, indica presencia cuantificable de virus.

A tubérculos infectados con PVY del CV. Melita, se les rompió la dormancia con Rindite y se plantaron en macetas. A los 25 días de postemergencia de brotes se tomó la primera muestra de follaje (una o dos hojas de los sectores apical, medio y basal), para cuantificar el PVY. Inmediatamente después se realizó la primera aplicación de AV-100 y Citrol, de acuerdo a lo indicado en la Tabla 1. La aplicación se hizo con bomba de espalda con un volumen de $350 \mathrm{l} / \mathrm{ha}$ de agua, para conseguir mojar uniformemente al follaje. 
Tabla 1. Esquema del ensayo realizado.

\begin{tabular}{|c|c|c|c|c|c|c|c|c|}
\hline \multirow{2}{*}{$\begin{array}{l}\text { Momento de } \\
\text { aplicación }{ }^{*^{2}}\end{array}$} & \multicolumn{8}{|c|}{ Dosis de AV-100 } \\
\hline & \multicolumn{2}{|c|}{$0 \mathrm{l} / \mathrm{ha}$} & \multicolumn{2}{|c|}{$1.5 \mathrm{l} / \mathrm{ha}$} & \multicolumn{2}{|c|}{3 I/ha } & \multicolumn{2}{|c|}{$4.5 \mathrm{I} / \mathrm{ha}$} \\
\hline & CS & SS & CS & SS & CS & SS & CS & \\
\hline 25 & $8^{2}$ & 8 & 8 & 8 & 8 & 8 & 8 & 8 \\
\hline 25 y 50 & 8 & 8 & 8 & 8 & 8 & 8 & 8 & 8 \\
\hline
\end{tabular}

SS $=\sin$ Citrol

A los 50 días de post-emergencia se realizó la segunda determinación cuantificable de PVY y la aplicación de AV 100 y Citrol, de acuerdo a tratamiento inicial.

A los 75 días de post-emergencia, sólo se tomaron muestras para cuantificación de PVY y para determinar efectos de aplicaciones.

Se dejó secar, se cosechó y se seleccionó un tubérculo de cada maceta de 3.5 a $4.5 \mathrm{~cm}$ de diámetro, al que se le rompió la dormancia con Rindite. Se volvió a plantar en maceta y a los 25 días post-emergencia se sacaron las últimas muestras para determinar PVY.

Antes de analizar los datos se procedió a calcular los "delta" o incrementos de virus con respecto a la concentración inicial del mismo, con el fin de eliminar un factor que puede llevar a error al realizar el análisis estadístico, ya que la concentración inicial de virus es distinta para cada muestra del experimento.

En las tres fechas de muestreo que se tuvieron (25-50 y 75 días postemergencia), más el análisis a los 25 días post-emergencia de los tubérculos cosechados de los tratamientos anteriores, se calculó el incremento entre 25-50; 25-75 días post-emergencia y entre los 25 días desde la emergencia de los tubérculos sometidos a los análisis con los 25 días desde emergencia de tubérculos cosechados en este ensayo. De este cálculo se obtuvieron algunos resultados negativos y con el fin de evitarlos, se sumó el valor fijo de 1,200 que corresponde al incremento máximo obtenido.

Para estimar los efectos de la dosis de AV-100, del sinergista Citrol, de los momentos de aplicación y de las interacciones entre ellos, se 
hicieron análisis de la varianza, y se aplicó la prueba de comparaciones múltiples de Tukey.

\section{Resultados y Discusión}

\section{Concentración inicial de virus.}

La importancia de determinar ésta concentración inicial en el presente experimento se basa en lo indicado por Schuster et al, (1979), el cual señala que a medida que aumenta la concentración de virus, a una concentración de inhibidor estable, disminuye el efecto inhibitorio y por el contrario, a medida que aumenta la concentración del inhibidor, a una concentración de virus estable, aumenta el efecto inhibitorio. La Figura 1 muestra la concentración inicial de virus de las plantas de cada tratamiento.

El análisis de concentración inicial muestra la existencia de una gran variación entre los materiales empleados.

\section{Concentración inicial de PVY}

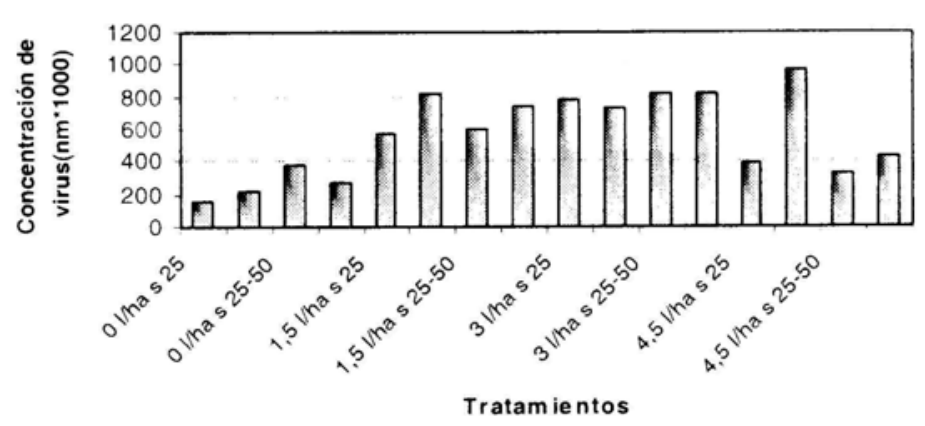

$S=\sin$ control

$C=$ con Control

25= Aplicación de AV-100 a los 25 días desde emergencia

25-50= Aplicación de AV100 a los 25 y 50 días desde emergencia

Figura 1. Concentración inicial de PVY en las plantas sometidas a los distintos tratamientos. 


\section{Evaluación de la concentración de virus a los 50 días desde emergencia:}

La Figura 2 muestra la concentración de virus a los 50 días postemergencia. Se observa un efecto positivo en la disminución de la concentración del virus en todos los tratamientos con AV-100. Los mejores resultados se obtuvieron con la dosis más alta sin Citrol, en relación al testigo y a la dosis inferior. El tratamiento de $4.5 \mathrm{I} / \mathrm{ha}$ con uso de Citrol produjo las mayores concentraciones de virus en los tratamientos con AV-100 (Figura 2).

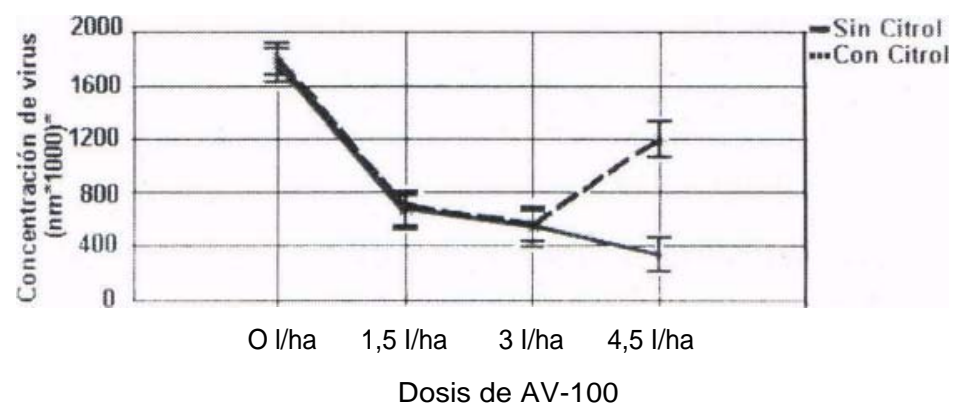

Figura 2. Interacción entre la dosis de AV-100 y el uso de Citrol a los 50 días post-emergencia.

El Citrol no mostró un efecto sinergista sobre la acción de AV-100, por el contrario, con la dosis máxima de AV-100 hay un aumento de la concentración de virus.

\section{Evaluación de la concentración de virus a los 75 días desde emergencia}

En esta etapa se deben observar resultados de las aplicaciones a los $25 \mathrm{y}$ 50 días. El análisis indica que hay respuestas positivas en la disminución de la concentración del virus con el uso de AV-100.

Existen diferencias en los tratamientos de dosis de AV-100 y en el tratamiento de momento de aplicación. Además hay diferencias significativas en las interacciones entre las dosis de AV-100 y el uso de Citrol (Figura 3) y entre el momento de aplicación y Citrol (Figura 4). 


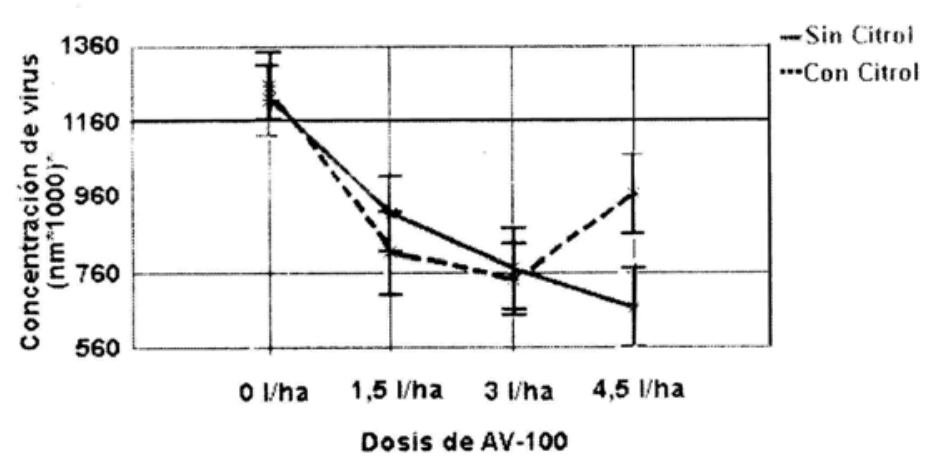

Figura 3. Interacción entre la dosis de AV-100 y el uso de CITROL a los 75 días post-emergencia.

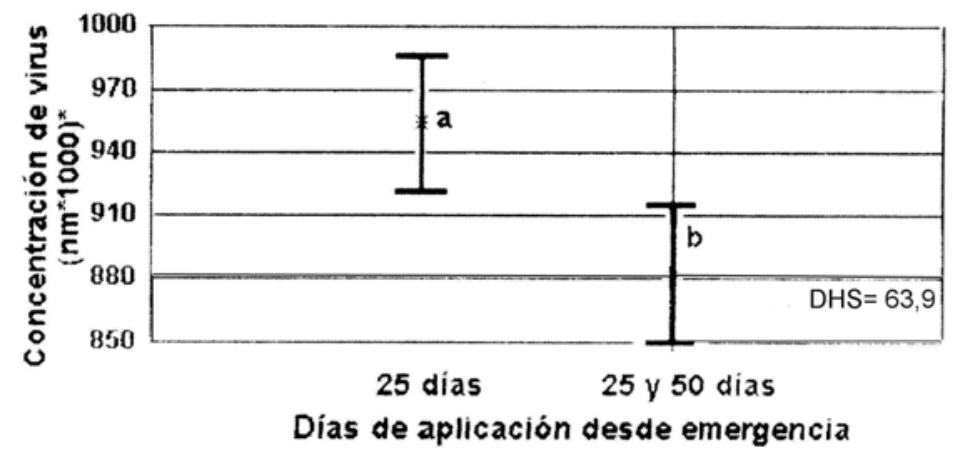

Figura 4. Efecto del número de aplicaciones de AV-100 sobre la concentración de virus a los 75 días desde emergencia. 
En la Figura 3 se observan resultados similares a los presentados en la Figura 2, no hay diferencias significativas entre las dosis de AV-100 con y sin Citrol, a excepción del tratamiento con $4.5 \mathrm{l} / \mathrm{ha}$. Esta última dosis sin Citrol disminuye en mayor grado la concentración de virus en la planta.

Analizando el efecto del número de aplicaciones se determina que dos aplicaciones de AV-100 a los 25 y 50 días desde emergencia, disminuyen en mayor grado la concentración de virus en la planta, en comparación con lo que sucede al efectuar una aplicación (Figura 4).

Cuando se usa Citrol, con una aplicación a los 25 días desde emergencia, se nota un efecto significativo (Figura 5). En cambio con dos aplicaciones, a los 25 y 50 días desde emergencia, no hay diferencias. Se puede observar además, que no hay diferencias entre una o dos aplicaciones de AV-100, sin uso de Citrol.

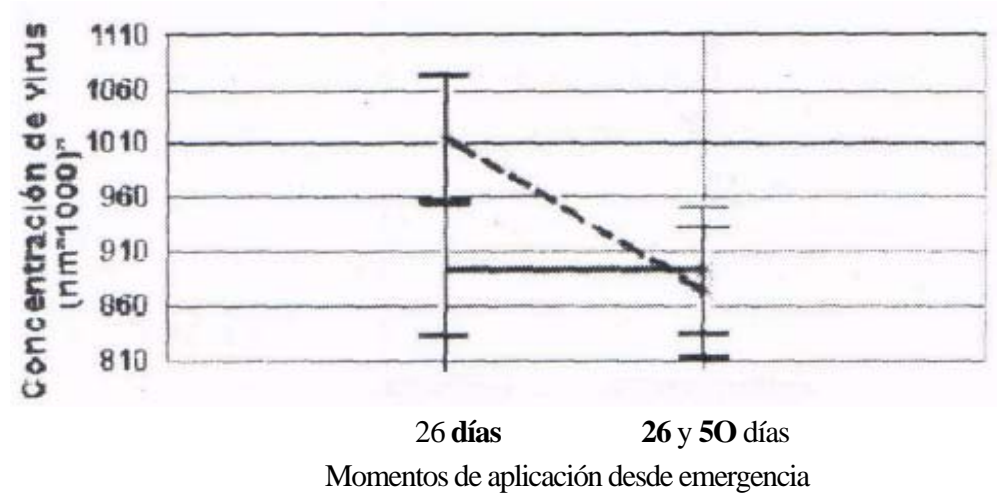

Figura 5. Interacción entre el momento de aplicación de AV-100 y el uso de Citrol a los 75 días post-emergencia.

Las Figuras 2 y 3 muestran que los testigos tuvieron la mayor concentración de virus durante el ensayo, siendo estas diferencias significativas en relación al resto de los tratamientos. Todos los tratamientos que recibieron AV-100 se comportaron de manera similar. Sin embargo, el tratamiento con mejores resultados en la disminución de virus fue la dosis más alta sin Citrol en relación al testigo y a la dosis inferior. Además, no hubo interacción entre las dosis de AV-100 usadas con el momento de aplicación de éstas. 
Los motivos de la disminución de virus se puede deber a numerosas causas, o a un conjunto de ellas. En primer lugar y de acuerdo a las especificaciones técnicas del agente antiviral AV-100, éste "basa su acción en la modificación de las estructuras externas del virus, específicamente de la hemoglutinina, evitando así, que éste pueda perforar la membrana celular de las células sanas".

Aún si el PVY tuviera hemaglutinina, el modo de acción del AV-100, podría ser similar al de la Amatadina y la Rimantadina (que son aminas tricíclicas), las cuales comparten 2 mecanismos de acción antiviral; primero bloquean una fase temprana de la replicación del virus, que tal vez constituye la pérdida de la cubierta proteica y segundo, actuando en una fase tardía del ensamblaje viral, quizás mediado por la alteración del procesamiento de la hemaglutinina (8).

Además se podría suponer que hay un efecto controlador del AV-100 disminuyendo, probablemente, la multiplicación del virus afectando su código genético; si así fuera, éste no se replicaría debido a que podría perder la capacidad de liberarse de su cubierta proteica, no permitiendo la liberación del virus, o por el contrario, podría formarse ARN viral, pero no tendría la capacidad de formar la cubierta proteica, que es necesaria para muchos virus vegetales para iniciar la infección (13).

Según Pizarro-Suárez (1980), hay modificaciones que se pueden inducir experimentalmente por agentes físicos y químicos, siendo la reacción más frecuente la pérdida de la infectividad, que resulta por la ruptura del virión o por algunos cambios en las proteínas o como se mencionó anteriormente, en su código genético. En algunos casos la inactivación es reversible y un virus ya inactivo puede reactivarse.

El aumento de la concentración de virus a los 75 días podría ser explicado, según lo descrito por Goodmann (1996), porque los compuestos actuales inhiben la replicación activa del virus, de tal manera que puede reanudarse la proliferación del mismo después de dejar de usar el antivirus.

Por otro lado, en las especificaciones técnicas de AV-100, se señala que este agente antiviral es obtenido de resinas naturales. De acuerdo a esto, existen ensayos de extractos vegetales de acción viricida obtenidas de, entre otras plantas, Boerhaaria diffusa (18), Cuscuta reflexa (1), Pseuderanthemum bicolor (19), Lentinus edodes, Yucca recurvifolia

\footnotetext{
${ }^{3}$ Comunicación personal de la Empresa FUMEX Ltda.
} 
Salisb (9), Cymopsis tetragonoloba (L.) (12), Operculina turpethum L. y Scilla indica Baker (11).

El método usado para evaluar estos viricidas provenientes de extractos vegetales ha sido preventivo, de tal manera que primeramente se asperja el extracto de las plantas y luego se inoculan éstas con el virus. Además la evaluación de productos que han presentado tener acción viricida, como el 2-alfa-hidroxibenzilbenzimidazole (7) entre otros, han sido evaluados bajo inoculaciones realizadas preventivamente -desde 4 a 8 días antes de la inoculación, y curativamente, desde 4 a 12 días después de la inoculación- y no bajo condiciones de plantas infectadas sistemáticamente.

De acuerdo a esto, los mejores resultados obtenidos por los viricidas descritos son en aspersiones muy cercanas al momento de la inoculación. Así Khan y Zaim (1992), obtuvieron los mejores resultados con aspersiones 24 horas antes de la inoculación y Fazio y Vicente (1991), tuvo los mejores resultados con Rivavarin $30 \mathrm{~min}$. después de la inoculación y con Tiasofurin aplicado 2 veces, a los 30 minutos y a los 5 días después de la inoculación.

Esto hace suponer que el control de los viricidas en plantas inoculadas pudiera ser mayor que en plantas infectadas sistémicamente, ya que la cantidad de inoculo en éstas últimas debiera ser más alto. Por lo tanto la acción de AV-100 por sí solo es positiva, solamente que en futuros ensayos se debiera evaluar el producto en plantas inoculadas, como preventivo y como curativo o comparativamente con algún viricida antes citado.

\section{Muestreo realizado a los 25 días post-emergencia de los tubérculos cosechados de plantas sometidas a tratamientos anteriores}

Las concentraciones de virus analizadas a los 25 días desde emergencia de los brotes de los tubérculos cosechados de los tratamientos anteriores resultaron tener diferencias significativas debido a las dosis de AV-100 utilizadas y al uso de Citrol: además hubo un efecto de interacción entre ambos tratamientos.

Al igual que en los resultados obtenidos para el mismo tipo de interacción, se observa en la Figura 6 que no hay diferencias estadísticas en el uso de Citrol, a excepción del tratamiento con $4.5 \mathrm{l} / \mathrm{ha}$, en el cual el uso de Citrol provocó un aumento en la concentración de virus; este aumento significó que este tratamiento se comportara estadísticamente igual a los tratamientos testigo $(0 \mathrm{l} / \mathrm{ha})$. 
Además se puede observar que todos los tratamientos en los cuales se aplicó AV-100, con o sin uso de Citrol, se comportan estadísticamente de similar manera (excepto el tratamiento con $4.5 \mathrm{l} / \mathrm{ha}$ con Citrol), siendo el tratamiento con la dosis más alta sin Citrol el que produjo mejores resultados.

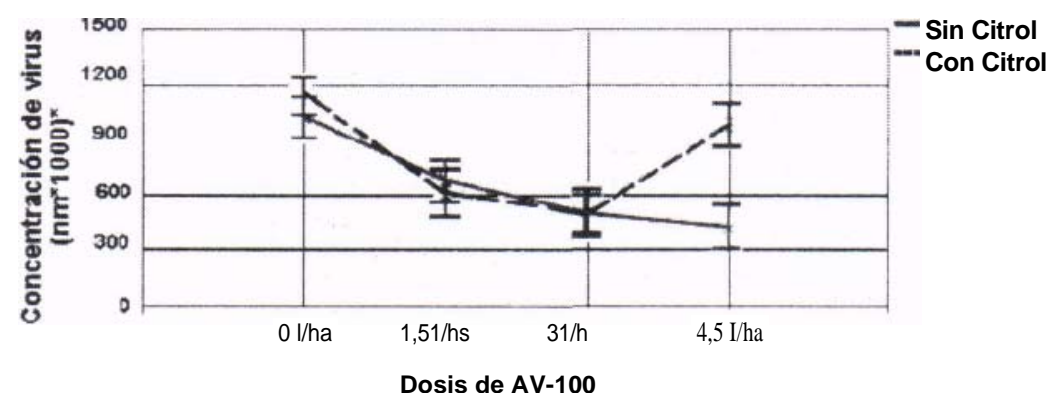

Figura 6. Interacción entre el momento de aplicación de A V-100 y el uso de Citrol a los 25 días desde emergencia de los tubérculos cosechados, de los tratamientos anteriores.

\section{Conclusiones}

1. El producto PVY AV-100 provoca una disminución de la concentración de virus en las plantas de papa, pero no lo elimina.

2. Esta disminución se intensifica cuando el producto se aplica en dosis mayores.

3. El producto Citrol, no mostró acción viricida y no tuvo un efecto sinergista al ser aplicado con el viricida AV-100.

4. No hay un efecto de disminución de virus con el número de aplicaciones de AV-100.

\section{Referencias Bibliográficas}

1. Awasthi, L, P. 1981. The purification and nature of an antiviral protein from Cuscuta reflexa plants. Archives of Virology 70: 215-233. 
2. Banttari, E.; Ellis, P.; Khurana, P. 1993. Management of diseases caused by viruses and viruslike pathogens. In: Rowe, (ed.) Potato Health Management. The American Phytopathological Society. Minnesota, Estados Unidos de Norteamérica. 127-134 p.

3. Chile, Servicio Agrícola y Ganadero (SAG). 1994. Normas generales y específicas de certificación de semillas. Ministerio de Agricultura, Servicio Agrícola y Ganadero. Chile. 109 p.

4. Centro Internacional De La Papa (CIP). 1993. Serología. In: Jayasinghe, U. y Salazar, L, ed. Manual de técnicas en virología de plantas. Unidad Técnica de Capacitación 1 (TTU). CIP, Lima, Perú. p. 1-4.

5. Dawson, W. O. 1984. Effects of animal antiviral chemicals on plant viruses. Phytopathology 74:211-213.

6. Fazio, G.; Vicente, M. 1991. Antiphytoviral drugs against tomato spotted virus. Turrialba 41(2):244-253.

7. Fraser, R.; Gerwitz, A. 1984. Effects of 2-alphahydroxybenzimidazole on tobáceo mosaic virus and host RNA synthesis in tobaco leaf discs and plants. Plant Science Letters

8. Goodman, A. 1996. Las bases farmacológicas de la terapéutica. $9^{a}$ Edición. Volumen 2. McGraw-Hill Interamericana. Atlampa, México. 1996 p.

9. Hiramatsu, A.; Norifumi. K.; Naofumi, D. 1987. Properties of two inhibitors of plant virus infection from fruiting bodies of Lentinus edades and from leaves of Yucca recurvifolia Salibs. Agricultur. Biological Chemistry $51: 897-904$.

10. Horzinek, M. C. 1980. Compendio de virología general. $1^{a}$ edición. Hemisferio Sur. Buenos Aires, Argentina. 174 p.

11. Kahn, A.; Zaim, M. 1992. Physiochemical properties and mode of action of inhibitors of plant virus replication present in Operculina turpethum L. and Scilla indica Baker. Zeitschrift für Pflanzenkrankheiten und Pflanzenschutz 99(1):71-79.

12. Kahn, M.; Abid Ali, M. y Verma, N. 1990. Partial characterization of an induced virus inhibitory protein, asociated with systemic resistance in Cyampopsis tetragonoloba (L.) Taub. plants. Annals Applied Biology 1 17:617-623.

13. Matthews, R. 1991. Plant Virology. Third Edition. Academic Press. E. U. San Diego, Estados Unidos de Norteamérica. 835 p. 
14. Salazar F., L. 1995. Los virus de la papa y su control. Centro Internacional de la Papa (CIP), Lima, Perú. 226 p.

15. Schulze, S. 1995. The mode of inhibition of TMV- and PVX-induced RNA-dependent RNA polymerases by some antiphytoviral drugs. Journal of Phytopatology 141(1):77-85.

16. Schuster, G.; Höringklee, W.; Winter, H.; Esser, G.; Steinke, U.; Kochmann, W.; Kramer, W.; Steinke, W. 1979. Antiphytoviral activity of 2,4-dioxo-hexahydro-triazine. Acta Virol. (23):412-420.

17. Stryer, L. 1988. Bioquímica. 3- Edición. Reverte, Barcelona, España. 1084 p.

18. Verma, H.; Awasthi, L. 1979. Antiviral activity of Boerhaavia diffusa root extract and the physical properties of the virus inhibitor. Canadian Journal of Botany 57:1214-1217.

19. Verma, H.; Kahn, M. y Abid Ali, M.1984. Management of plant virus diseases by Pseuderanthemum bicolor leaf extract. Zeitschrift für Pflanzenkrankheiten und Pflanzenschutz 91:266-272. 